\title{
Risk of sudden coronary death based on genetic background in Chinese Han population
}

\author{
NENGHUA ZHANG ${ }^{1 *}$, XIAOCHUN LV ${ }^{2 *}$, XIAOJUAN CHENG ${ }^{3}$, JIAQI WANG $^{3}$, JINDING LIU $^{3}$,

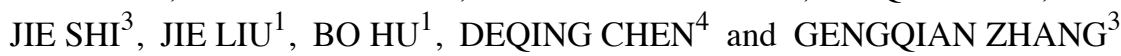

${ }^{1}$ Department of Clinical Laboratory and Pathology, Municipal Key-Innovative Discipline of Molecular Diagnostics, Jiaxing Hospital of Traditional Chinese Medicine, Jiaxing University, Jiaxing, Zhejiang 314001; ${ }^{2}$ Department of Cardiovascular Medicine, Fenyang Hospital of Shanxi Province, Fenyang Hospital Affiliated to Shanxi Medical University, Fenyang, Shanxi 032200; ${ }^{3}$ Department of Forensic Biology, School of Forensic Medicine, Shanxi Medical University, Jinzhong, Shanxi 030619; ${ }^{4}$ Department of Pathology, Forensic and Pathology Laboratory, Judicial Expertise Center, Jiaxing University Medical College, Jiaxing, Zhejiang 314001, P.R. China

Received March 13, 2021; Accepted July 8, 2021

DOI: $10.3892 / \mathrm{etm} .2021 .10502$

\begin{abstract}
Associations between gene variations and sudden cardiac arrest or coronary artery disease have been reported by genome-wide association studies. However, the implication of the genetic status in cases of sudden coronary death (SCD) from the Chinese Han population has remained to be investigated. The present study established a mini-sequencing system to examine putative death-causing single nucleotide polymorphisms (SNPs) using multiplex PCR, single base extension reaction and capillary electrophoresis techniques. A total of 198 samples from the Chinese Han population (age range, 34-71 years; mean age, 53.86 years) were examined using this
\end{abstract}

Correspondence to: Dr Deqing Chen, Department of Pathology, Forensic and Pathology Laboratory, Judicial Expertise Center, Jiaxing University Medical College, 118 Jiahang Road, Jiaxing, Zhejiang 314001, P.R. China

E-mail: dqchen@zjxu.edu.cn

Professor Gengqian Zhang, Department of Forensic Biology, School of Forensic Medicine, Shanxi Medical University, 55 Wenhua Street, Jinzhong, Shanxi 030619, P.R. China

E-mail: gengqianzhang@sxmu.edu.cn

*Contributed equally

Abbreviations: AUC, area under the receiver operating characteristic curve; CAD, coronary artery disease; CE, capillary electrophoresis; CHD, coronary heart disease; GWAS, genome-wide association study; MDR, multifactor dimensionality reduction; NGS, next-generation sequencing; OR, odds ratio; rSAP, recombinant shrimp alkaline phosphatase; SBE, single base extension; SCD, sudden coronary death; SNP, single nucleotide polymorphism; WES, whole-exome sequencing; WGS, whole-genome sequencing

Key words: sudden coronary death, SNaPshot, single nucleotide polymorphism, coronary heart disease, capillary electrophoresis method. Samples were classified into three groups: Coronary heart disease (CHD, $n=70), \operatorname{SCD}(n=53)$ and control $(n=75)$ group. Significant associations were identified for 10, 4 and 6 SNPs in CHD, SCD and sudden death from CHD, respectively, using the $\chi^{2}$ test. The SNPs obtained by binary logistic regression may be used to assess and predict the risk of disease. The predictive accuracy of the SNPs in each prediction model and their area under the receiver operating characteristic curve (AUC) values were determined. The AUC of the four SNPs (rs12429889, rs10829156, rs16942421 and rs12155623) to predict CHD was 0.928, the AUC of the six SNPs (rs2389202, rs2982694, rs10183640, rs597503, rs16942421 and rs12155623) to predict SCD was 0.922 and the AUC of the four SNPs (rs16866933, rs4621553, rs10829156 and rs12155623) to predict sudden death from CHD was 0.912. The multifactor dimensionality reduction values were as follows: 0.8690 (prediction model of CHD), 0.7601 (prediction model of SCD) and 0.7628 (prediction model of sudden death from CHD). Taken together, the results of the present study suggested that these SNPs have considerable potential for application in genetic tests to predict CHD or SCD. However, further studies are required to investigate the putative functions of these SNPs.

\section{Introduction}

Sudden coronary death (SCD) is the most common type of sudden death in adults, particularly in middle-aged and elderly individuals (1). SCD primarily occurs when coronary atherosclerosis results in acute myocardial ischemia and there is a sudden interruption to coronary blood flow (2-4). SCD frequently occurs after an inducement, such as drinking alcohol, fatigue, smoking or exercise, and may be fatal within a small number of hours, whereby certain individuals pass away during their sleep (5). Previous studies have reported that $\sim 80 \%$ of SCDs are associated with the existence of coronary artery disease (CAD), which is the most common underlying cause in adults $(6,7)$. Several epidemiological studies have demonstrated that a family history of SCD is an 
independent risk factor of SCD and patients with different gene mutations may have similar symptoms $(8,9)$. Genetic studies in the past three decades have highlighted the genetic changes of patients with inherited cardiac disease that cause SCD $(10,11)$. Genome-wide association studies (GWAS) are a systemic tool used to evaluate the whole genome to determine the association between gene variants and diseases $(12,13)$. Sudden cardiac arrest caused by CAD has been identified in GWAS $(14,15)$. However, whether these single nucleotide polymorphisms (SNPs) obtained by GWAS that are associated with sudden cardiac arrest or coronary heart disease (CHD) are directly associated with SCD has remained elusive.

Studies on SCD have not been performed in terms of risk gene variations in the Chinese Han population and the underlying genetics that contribute to the SCD single nucleotide variations are of significant interest. When using comparable population groups, it is important to determine the genetic background of an alive individual with CHD and that of individuals who experienced SCD with CHD, which may help understand the predictive value and association between the genetic changes and incidence of SCD to improve SCD prevention measures. Forensic practitioners frequently encounter cases of sudden death for unknown reasons during autopsy. Thus, genetic predictive studies will help determine the cause of death, particularly for those patients who died of CHD.

The majority of biological tissue specimens degrade due to external exposure prior to examination and improper treatment, such as implementation of paraffin-embedded tissues and formalin-fixed human tissues $(16,17)$. Degraded biological specimens are not used for GWAS, whole-genome sequencing (WGS) or whole-exome sequencing (WES), which impedes the application of these techniques in forensic examinations of cases of SCD (18-21). It has been reported that SCD-related SNPs may contribute to SCD, which is easily detected in degraded samples.

The present study developed an assay with mini-sequencing techniques based on the GWAS results of clinical samples reported by Aouizerat et al (14) to investigate the genetic background of SCD in the Chinese Han population. This assay applies to most degraded tissues and is yet to be confirmed for use in other populations to identify risk factors, as well as provide accurate diagnoses and prevention advice for first-degree relatives.

\section{Materials and methods}

Sample collection. A total of 198 samples were collected from the Chinese Han population. The clinical characteristics of all participants are presented in Table SI. Samples were classified into three groups: The CHD $(n=70), \operatorname{SCD}(n=53)$ and control $(n=75)$ groups. The CHD group consisted of blood samples from 70 patients with CHD. The SCD group consisted of 53 cases in which SCD was confirmed following autopsy after death. The control group consisted of 24 cases that died from other causes (such as trauma, poisoning, suffocation, etc.) and 51 volunteers who had no family history of SCD and CHD. The clinical characteristics were not available for the anonymous healthy controls. Sample data are presented in Table I. The sex ratio (male/female) was 3.67 (55/15), 4.89 (44/9) and
3.69 (59/16) in the CHD, SCD and control groups, respectively, with respective median ages (range) in each group of 52 (40-69), 52.5 (37-71) and 53 (34-69) years for the males, and 58 (45-70), 61 (47-68) and 55.5 (48-68) years for the females. Comparisons between the three groups demonstrated no significant differences in sex, age and other complicated diseases. Genomic DNA was extracted from venous blood using the E.Z.N.A ${ }^{\mathrm{TM}}$ SE Blood DNA kit (Omega Bio-Tek, Inc.). Tissues were treated using the Mag-Blind ${ }^{\circledR}$ Tissue DNA kit M6223 (Omega Bio-Tek, Inc.) according to the manufacturer's instructions. DNA samples were quantified at an optical density of $260 \mathrm{~nm}$ using a BioSpectrometer (22331; Eppendorf AG). The extracted DNA samples were subsequently diluted with highly purified water to the final concentration of $10 \mathrm{ng} / \mu \mathrm{l}$ and stored at $-20^{\circ} \mathrm{C}$ until subsequent analysis.

Establishment of the SNaPshot assay. The SNaPshot kit (ABI PRISM $^{\circledR}$ SNaPshot ${ }^{\mathrm{TM}}$ Multiplex kit; Thermo Fisher Scientific, Inc.) was used to establish a mini-sequencing method for SNP screening in a combination of the multiplex PCR, single base extension (SBE) and capillary electrophoresis (CE) techniques.

\section{Construction of a multiplex PCR system}

Candidate SNPs. The sudden cardiac arrest-related gene variations were selected from GWAS results. To determine whether the polymorphisms of these SNPs are prone to induce SCD in the Chinese Han population, 21 SNPs with $\mathrm{P}<1 \times 10^{-7}$ were selected from GWAS, based solely on previous studies (22-25). The results revealed that the 21 SNPs were independent and did not exhibit any linkage disequilibrium cluster. Data on the SNPs are presented in Table II.

Multiplex PCR. The multiplex PCR primers were designed using the online software Primer 3.0 (http://primer3. ut.ee). The specificity of the primers was confirmed using National Center for Biotechnology Information Primer Blast (https://www.ncbi.nlm.nih.gov/tools/primer-blast/ index.cgi?LINK_LOC=BlastHome). Auto Dimer v1 software was used to assess the primer-dimer and hairpin structures $(26,27)$. In forensic medicine, most samples experience a period of ex vivo degradation prior to the DNA test and even during the fixation procedure with formaldehyde $(28,29)$. Thus, PCR with short fragment amplification (132-280 bp) was performed, which was amenable to type-degraded DNA samples in forensic casework. The primer sequences are listed in Table III. PCR amplification was performed using the GeneAmp PCR System 9700 (Applied Biosystems; Thermo Fisher Scientific, Inc.). The PCR mixture had a total volume of $10 \mu 1$, containing $5 \mu 12 \mathrm{X}$ Multiplex PCR mix (M5 HiPer Multiplex PCR MasterMix; Mei5 Bioservices Co., Ltd.), $1 \mu 1$ PCR primer mix (the final concentration of each primer was $0.2 \mu \mathrm{M}$ ) and $5 \mathrm{ng}$ DNA template. The following thermocycling conditions were used: Initial denaturation at $95^{\circ} \mathrm{C}$ for $10 \mathrm{~min}$, followed by 30 cycles of $94^{\circ} \mathrm{C}$ for $20 \mathrm{sec}, 58^{\circ} \mathrm{C}$ for $20 \mathrm{sec}$ and $72^{\circ} \mathrm{C}$ for $30 \mathrm{sec}$, and a final extension at $72^{\circ} \mathrm{C}$ for $5 \mathrm{~min}(30)$.

\section{Construction of the mini-sequencing system}

SBE primers. SBE primers were designed to pair the bases adjacent to the expected position of the SNP. To isolate 
Table I. Sample data of the present study.

\begin{tabular}{lcrrrr}
\hline Group & Sex & N $(\%)$ & Sex ratio $(\mathrm{M} / \mathrm{F})$ & Age, years & $\begin{array}{r}\text { Patients complicated } \\
\text { with other diseases, \% }\end{array}$ \\
\hline CHD & M & $55(78.57)$ & $3.67: 1$ & $52(40-69)$ & 20 \\
& F & $15(21.43)$ & & $58(45-70)$ & 20 \\
SCD & M & $44(83.02)$ & $4.89: 1$ & $52.5(37-71)$ & 22 \\
& F & $9(16.98)$ & & $61(47-68)$ & None recorded \\
Control & M & $59(78.67)$ & $3.69: 1$ & $53(34-69)$ & None recorded \\
& F & $16(21.33)$ & & $55.5(48-68)$ & \\
\hline
\end{tabular}

Age is expressed as median (range). M, male; F, female.

Table II. Information of 21 SNPs in the present study.

\begin{tabular}{|c|c|c|c|c|c|c|}
\hline SNP & Allele & Context & Gene & $\begin{array}{c}\text { Location } \\
\text { (GRCh38.p12) }\end{array}$ & $\begin{array}{l}\text { P-value from } \\
\text { GWAS }\end{array}$ & $\begin{array}{l}\text { Population } \\
\text { by GWAS }\end{array}$ \\
\hline rs 2389202 & $\mathrm{~A} / \mathrm{T}$ & Intergenic & MIR1973, TRMT112P1 & Chr4: 116333133 & $4.000 \times 10^{-7}$ & European \\
\hline rs11624056 & $\mathrm{A} / \mathrm{T}$ & Intergenic & FLRT2, GALC & Chr14: 87039904 & $3.000 \times 10^{-8}$ & European \\
\hline rs2982694 & $\mathrm{G} / \mathrm{T}$ & Intron & ESR1 & Chr6: 151964552 & $7.000 \times 10^{-10}$ & European \\
\hline rs4665058 & $\mathrm{A} / \mathrm{C}$ & Intron & BAZ2B & Chr2: 159333698 & $2.000 \times 10^{-10}$ & European \\
\hline rs17718586 & $\mathrm{G} / \mathrm{T}$ & Intergenic & CALM2P1, CASC17 & Chr17: 70648048 & $2.000 \times 10^{-8}$ & European \\
\hline rs12429889 & $\mathrm{T} / \mathrm{C}$ & Intergenic & KLF12, RNY1P5 & Chr13: 74168185 & $5.000 \times 10^{-20}$ & European \\
\hline rs16866933 & $\mathrm{G} / \mathrm{A}$ & Intron & ZNF385B & Chr2: 179701951 & $6.000 \times 10^{-14}$ & European \\
\hline rs7307780 & $\mathrm{C} / \mathrm{T}$ & Intergenic & RPL10P13, PHLDA1 & Chr12: 75826838 & $5.000 \times 10^{-15}$ & European \\
\hline rs17291650 & $\mathrm{A} / \mathrm{G}$ & Cds-synon & ATF1 & Chr12: 50819650 & $3.000 \times 10^{-7}$ & European \\
\hline rs9581094 & $\mathrm{T} / \mathrm{C}$ & Intron & PARP4 & Chr13: 24508492 & $7.000 \times 10^{-7}$ & European \\
\hline rs10183640 & $\mathrm{G} / \mathrm{A}$ & Intergenic & ACVR1, UPP2 & Chr2: 157923692 & $5.000 \times 10^{-7}$ & European \\
\hline rs12189362 & $\mathrm{C} / \mathrm{T}$ & Intron & GRIA1 & Chr5: 153677988 & $3.000 \times 10^{-10}$ & European \\
\hline rs11187837 & $\mathrm{A} / \mathrm{G}$ & Intron & PLCE1 & Chr10: 94276223 & $4.000 \times 10^{-7}$ & European \\
\hline rs4621553 & G/A & Intergenic & YTHDC2, KCNN2 & Chr5: 113694467 & $4.000 \times 10^{-8}$ & European \\
\hline rs 1559040 & $\mathrm{C} / \mathrm{T}$ & Intron & ACYP2 & Chr2: 54120613 & $4.000 \times 10^{-8}$ & European \\
\hline rs10829156 & $\mathrm{A} / \mathrm{G}$ & Intron & ARL5B & Chr10: 18661626 & $4.000 \times 10^{-7}$ & European \\
\hline rs2281680 & $\mathrm{G} / \mathrm{A}$ & Intron/ncRNA & $\mathrm{AP} 1 \mathrm{G} 2$ & Chr14: 23563861 & $6.000 \times 10^{-8}$ & European \\
\hline rs597503 & $\mathrm{G} / \mathrm{A} / \mathrm{C}$ & Intergenic & SCML2P1, LAMA1 & Chr18: 6939948 & $2.000 \times 10^{-8}$ & European \\
\hline rs16942421 & $\mathrm{G} / \mathrm{A} / \mathrm{T}$ & Intron & KCTD1 & Chr18: 26576461 & $8.000 \times 10^{-10}$ & European \\
\hline rs12155623 & $\mathrm{A} / \mathrm{C} / \mathrm{T}$ & Intergenic & EFCAB1, SNAI2 & Chr8: 48899642 & $3.000 \times 10^{-7}$ & European \\
\hline rs2251393 & $\mathrm{G} / \mathrm{A} / \mathrm{C}$ & UTR-3 & 10-Mar & Chr17: 62701571 & $4.000 \times 10^{-7}$ & European \\
\hline
\end{tabular}

Chr, chromosome; SNP, single nucleotide polymorphism; GWAS, genome-wide association study; ncRNA, non-coding RNA.

each SBE product in the following CE, -(CT) $)_{n}$ or -(AGCT) $n$ (' $n$ ' indicates the number of repetitions) tails were added at the 5'-end of each SBE primer, according to the length to be detected. In this experiment, the length of expected SBE products ranged between $20-82 \mathrm{bp}$. SBE primer sequences are listed in Table III.

Purification and SBE reaction. Recombinant shrimp alkaline phosphatase (rSAP; New England BioLabs, Inc.) was adopted to remove excessive deoxyribonucleoside triphosphate (dNTP) from the PCR product and exonuclease I (Exo I; New England BioLabs, Inc.) for excessive PCR primers. The purification reaction was performed in a total volume of $5 \mu 1$, containing $3.5 \mu \mathrm{l}$ PCR product, $0.5 \mathrm{U}$ rSAP and $4 \mathrm{U}$ Exo I. The reaction mixture was incubated at $37^{\circ} \mathrm{C}$ for $1 \mathrm{~h}$, followed by $95^{\circ} \mathrm{C}$ for $15 \mathrm{~min}$. The purified PCR products were subjected to an SBE reaction in a total volume of $5 \mu \mathrm{l}$, containing $2 \mu \mathrm{l}$ purified PCR products, $2.5 \mu \mathrm{l}$ SNaPshot reaction mix (SNaPshot $^{\mathrm{TM}}$ Multiplex kit; Applied Biosystems; Thermo Fisher Scientific, Inc.) and $0.5 \mu \mathrm{l} \mathrm{SBE}$ primer mixtures (the concentration of the primers was displayed in Table III). The SBE reaction conditions were as follows: $96^{\circ} \mathrm{C}$ for $5 \mathrm{sec}, 50^{\circ} \mathrm{C}$ for $10 \mathrm{sec}$ and $60^{\circ} \mathrm{C}$ for $15 \mathrm{sec}$ for 35 cycles. rSAP was adopted to remove excessive dideoxyNTP (ddNTP) prior to CE. 
Table III. PCR and SBE primers used in the study.

\begin{tabular}{|c|c|c|c|c|}
\hline SNP & PCR primer sequence $\left(5^{\prime}-3^{\prime}\right)$ & $\begin{array}{l}\text { Product } \\
\text { length, } \\
\text { bp }\end{array}$ & SBE primer sequence $\left(5^{\prime}-3^{\prime}\right)$ & $\begin{array}{c}\text { SBE primer } \\
\text { concentration, } \\
\mu \mathrm{M}\end{array}$ \\
\hline rs2389202 & $\begin{array}{l}\text { F: TGAACTTCATTGCCATAGTCTCC } \\
\text { R: GAAGAGACACTGGCCCTCT }\end{array}$ & 185 & TTGGAAAAGATAAAGTCACA & 0.20 \\
\hline rs11624056 & $\begin{array}{l}\text { F: TGTACACTGCTCGGTGATGG } \\
\text { R: ACGTCTCTCAGGCTTCTCCA }\end{array}$ & 170 & $(\mathrm{GACT})_{1}$ AAATCTCAGAAATCACCACT & 0.01 \\
\hline rs2982694 & $\begin{array}{l}\text { F: CCAAGTATTTTGCTGTTGTTGCT } \\
\text { R: CTGGGTGACAGAGTGAGACT }\end{array}$ & 280 & $(\mathrm{GACT})_{2}$ TTACTGCATTTGTTTATCAG & 1.65 \\
\hline rs4665058 & $\begin{array}{l}\text { F: CGCGACATGTAACCAGAAATCA } \\
\text { R: CCGACCATTTTAGACTTTCCCAG }\end{array}$ & 145 & $(\mathrm{CT})_{5}$ TCTTAAAAACAAAATAGCTT & 1.25 \\
\hline rs 17718586 & $\begin{array}{l}\text { F: CCATGTCTTCAGCTACACACAG } \\
\text { R: GCAGCATATACAACACCTAGCATAG }\end{array}$ & 198 & $(\mathrm{GACT})_{3} \mathrm{CTACCTGTATCAAAGTAAAT}$ & 0.02 \\
\hline rs12429889 & $\begin{array}{l}\text { F: AGCGTGCATCTTTCATTTCCT } \\
\text { R: GGCAAAGAATGGCTCACAGATAC }\end{array}$ & 178 & $(\mathrm{GACT})_{4}$ GCTTTGAAACGGTGGCTGTT & 0.50 \\
\hline rs16866933 & $\begin{array}{l}\text { F: CGTGGAAAGGAATGGGCAC } \\
\text { R: GCAATCTGGTCTCTTTGGGC }\end{array}$ & 143 & $(\mathrm{CT})_{9}$ TCCATCCTAAGCCTCCCAGA & 0.03 \\
\hline rs7307780 & $\begin{array}{l}\text { F: CCCAGAGTGTTTGCTGTTCC } \\
\text { R: GACATGCCTTTCACCTTCCAC }\end{array}$ & 176 & $(\mathrm{GACT})_{5}$ ATTAGTCTGTTCTCTCATTG & 0.35 \\
\hline rs 17291650 & $\begin{array}{l}\text { F: AGTGACCACGGAAAATTACTGAAG } \\
\text { R: TTTTCCAGGACTGCAACTCG }\end{array}$ & 166 & $(\mathrm{CT})_{11}$ TTTAGAGAAGCTGCTCGAGA & 0.06 \\
\hline rs9581094 & $\begin{array}{l}\text { F: GTGTTTCCTGGAAAAGTGACTCAT } \\
\text { R: GCCTAAGTGACAAAAGCGAGA }\end{array}$ & 205 & $(\mathrm{GACT})_{6} \mathrm{ATCTTGTTTTGCATTTTTCT}$ & 0.40 \\
\hline rs 10183640 & $\begin{array}{l}\text { F: CGATCAGTTTGGCTGGAGAGA } \\
\text { R: AAGCCTGGACAACATAGCGA }\end{array}$ & 177 & (CT) ${ }_{13}$ AGGAATTTGAACTTTATCTT & 0.10 \\
\hline rs12189362 & $\begin{array}{l}\text { F: CTCTTGGGGCTCCTGTAGAT } \\
\text { R: TCTTGCTGTGCTGGTTTGTC }\end{array}$ & 200 & $(\mathrm{GACT})_{7}$ TGCTAGAGAAGCTGTATTTC & 0.50 \\
\hline rs11187837 & $\begin{array}{l}\text { F: AGTTGCCCTTGAGTCAGCC } \\
\text { R: CACAAGTGGCCAGGTTTCA }\end{array}$ & 190 & $(\mathrm{CT})_{15} \mathrm{CACTCTGGGAAATGCAGGCT}$ & 0.55 \\
\hline rs4621553 & $\begin{array}{l}\text { F: GTTCAGATGCCTTTAGTTGCTGA } \\
\text { R: TGCTCATCTTGCCCAGATTTC }\end{array}$ & 174 & $(\mathrm{CT})_{17}$ TAGTTATACATTACTCAAGG & 0.10 \\
\hline rs 1559040 & $\begin{array}{l}\text { F: CGCATTGTGACTATCTGTTGGTA } \\
\text { R: CAGACCAGTAGCACAGCCT }\end{array}$ & 234 & $(\mathrm{GACT})_{9}$ TTGCCAGCCAGAAATCTCCA & 0.04 \\
\hline rs 10829156 & $\begin{array}{l}\text { F: GCCAGTCTTCAGAGTTTAGCATA } \\
\text { R: ACACGTCCCTTCTATTCGGT }\end{array}$ & 244 & $(\mathrm{CT})_{19}$ TCTCGTTTATTGATGTTTGA & 0.25 \\
\hline rs2281680 & $\begin{array}{l}\text { F: GAGGGCAGGACTCCAGAAAG } \\
\text { R: TGAGGCATGGACCAGGATG }\end{array}$ & 150 & $(\mathrm{CT})_{21}$ CATGGAAACCTCTTTCTCCT & 0.02 \\
\hline rs597503 & $\begin{array}{l}\text { F: GGAGATGAATGGTAGTGGTTGC } \\
\text { R: TGGTGCCAAAAGTCCTTGTT }\end{array}$ & 164 & $(\mathrm{CT})_{23}$ TGAATTTCATGGAAATGTAC & 0.15 \\
\hline rs 16942421 & $\begin{array}{l}\text { F: CCCTTGCTGAGATTTGGGTG } \\
\text { R: CGTTCGAAATGGCTGCTAGG }\end{array}$ & 203 & $(\mathrm{CT})_{27}$ AAAATACATTTGAATGTACT & 0.30 \\
\hline rs 12155623 & $\begin{array}{l}\text { F: GTAGGGCTGAAGAACATGCAAT } \\
\text { R: GCTTCAGCACCCCACAAAAC }\end{array}$ & 132 & $(\mathrm{CT})_{29}$ GGCTTTGGGTGGAAAAGAAC & 0.04 \\
\hline rs2251393 & $\begin{array}{l}\text { F: GCTGCCCATAGATGCTCAAG } \\
\text { R: AGCCCTTCTTTCTACGTCCC }\end{array}$ & 134 & $(\mathrm{CT})_{31}$ ACCCCAAAAGAGAGTGGCAC & 0.05 \\
\hline
\end{tabular}

F, forward; R, reverse; SBE, single base extension; SNP, single nucleotide polymorphism.

Separation and visualization by $C E$. To visualize the SBE products, $1.5 \mu \mathrm{l} \mathrm{SNaPshot}$ reaction products were mixed with $10 \mu \mathrm{l} \mathrm{Hi-Di}$ formamide (Applied Biosystems; Thermo Fisher Scientific, Inc.) and $0.1 \mu \mathrm{l}$ of GeneScan ${ }^{\mathrm{TM}} 120 \mathrm{LIZ}^{\mathrm{TM}}$ size standard (Applied Biosystems; Thermo Fisher Scientific, Inc.). The mixture was denatured at $95^{\circ} \mathrm{C}$ for $5 \mathrm{~min}$, followed by incubation at $0^{\circ} \mathrm{C}$ for $3 \mathrm{~min}$. A 3130 genetics analyzer (Applied Biosystems; Thermo Fisher Scientific, Inc.) with a $36-\mathrm{cm}$ 


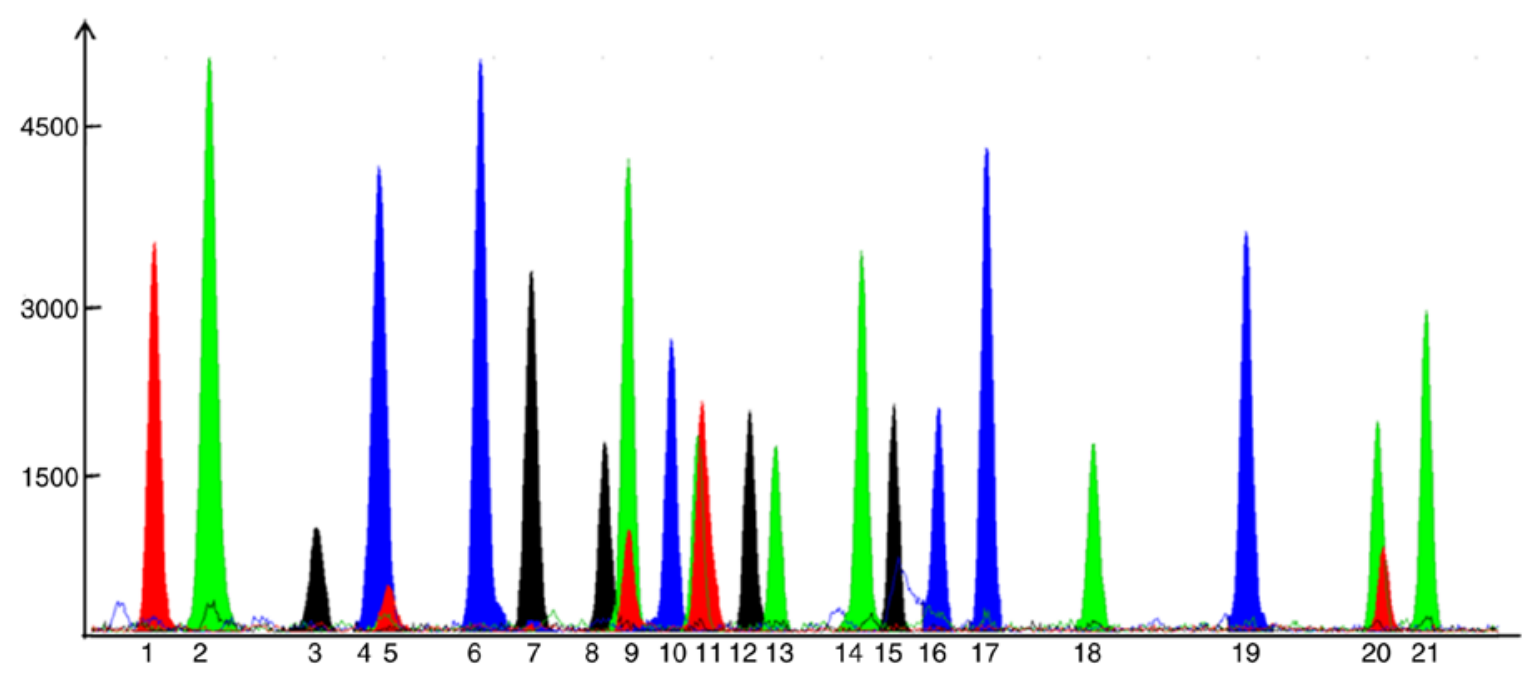

Figure 1. Results of 21 single nucleotide polymorphisms from a random individual from the control group. Blue represents guanine, green represents adenine, black represents cytosine and red represents thymine. Signals: 1, rs2389202; 2, rs11624056; 3, rs4665058; 4, rs17718586; 5, rs2982694; 6, rs16866933; 7, rs12429889; 8, rs7307780; 9, rs17291650; 10, rs10183640; 11, rs9581094; 12, rs12189362; 13, rs11187837; 14, rs4621553; 15, rs1559040; 16, rs10829156; 17, rs2281680; 18, rs597503; 19, rs16942421; 20, rs12155623; and 21, rs2251393.

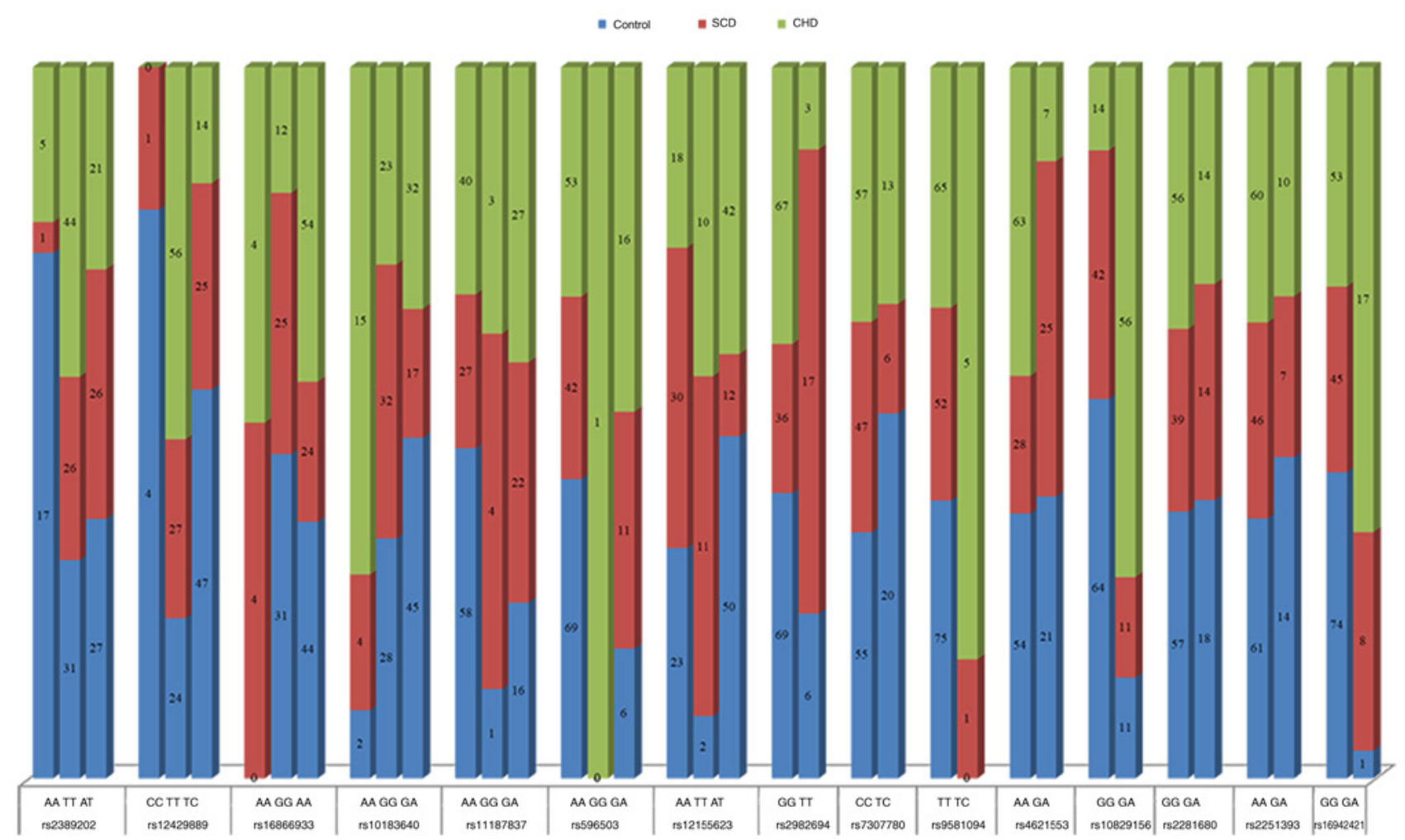

Figure 2. Results of 15 SNPs in each group. Blue represents the control group, red represents the SCD group and green represents the CHD group. Genotype data for these 15 SNPs are presented in Table SII. SNP, single nucleotide polymorphism; CHD, coronary heart disease; SCD, sudden coronary death.

capillary filled with POP-4 gel (Applied Biosystems; Thermo Fisher Scientific, Inc.) was used to detect the SNP genotype. Mutated or normal SNPs were analyzed using GeneMapper ID v3.2 software (Applied Biosystems; Thermo Fisher Scientific, Inc.), based on different fluorescent signals.

Sensitivity of the SNaPshot assay. To further evaluate the detection sensitivity of the mini-sequencing system, multiplex PCR and SBE procedures were performed using 10, 1, 0.1 and
$0.01 \mathrm{ng}$ template DNA, respectively. The results are presented in Fig. S1. All experiments were performed in triplicate. Full SNP profiles were detected with $0.1 \mathrm{ng}$ human genomic DNA.

Accuracy of the mini-sequencing system. Samples were randomly sampled for single PCR and sent to Thermo Fisher Scientific, Inc. for Sanger sequencing to verify the accuracy of the experiment. The results were consistent with those of the mini-sequencing assay established in this experiment (Fig. S2). 
Table IV. Results of 15 SNPs compared with the $\chi^{2}$ test among three groups of samples.

A, Comparison between control group and CHD group

\begin{tabular}{|c|c|c|c|c|c|}
\hline SNP & Allele & P-value & Risk allele & Odds ratio & $95 \% \mathrm{CI}$ \\
\hline rs2389202 & $\mathrm{A}>\mathrm{T}$ & 0.001 & A & 1.837 & $1.274-2.648$ \\
\hline rs12429889 & $\mathrm{T}>\mathrm{C}$ & $<0.0001$ & $\mathrm{C}$ & 3.667 & 2.138-6.290 \\
\hline rs16866933 & $\mathrm{G}>\mathrm{A}$ & 0.008 & G & 1.268 & $1.059-1.519$ \\
\hline rs10183640 & $\mathrm{G}>\mathrm{A}$ & 0.042 & $\mathrm{G}$ & 1.209 & $1.004-1.454$ \\
\hline rs11187837 & $\mathrm{A}>\mathrm{G}$ & 0.010 & A & 1.151 & $1.032-1.284$ \\
\hline rs597503 & $\mathrm{G}>\mathrm{A}$ & 0.006 & A & 1.102 & $1.026-1.183$ \\
\hline rs12155623 & $\mathrm{A}>\mathrm{T}$ & 0.150 & A & 1.149 & $0.950-1.390$ \\
\hline rs2982694 & $\mathrm{G}>\mathrm{T}$ & 0.190 & $\mathrm{~T}$ & 1.867 & $0.720-4.839$ \\
\hline rs7307780 & $\mathrm{C}>\mathrm{T}$ & 0.278 & $\mathrm{~T}$ & 1.436 & $0.743-2.776$ \\
\hline rs9581094 & $\mathrm{T}>\mathrm{C}$ & 0.020 & $\mathrm{~T}$ & 1.037 & $1.004-1.071$ \\
\hline rs4621553 & $\mathrm{G}>\mathrm{A}$ & 0.010 & $\mathrm{G}$ & 2.800 & $1.229-6.382$ \\
\hline rs 10829156 & $\mathrm{G}>\mathrm{A}$ & $<0.0001$ & G & 1.544 & $1.339-1.781$ \\
\hline rs2281680 & $\mathrm{G}>\mathrm{A}$ & 0.587 & $\mathrm{G}$ & 0.978 & $0.902-1.060$ \\
\hline rs2251393 & $\mathrm{G}>\mathrm{A}$ & 0.499 & $\mathrm{G}$ & 1.307 & $0.600-2.845$ \\
\hline rs 16942421 & $\mathrm{G}>\mathrm{A}$ & $<0.0001$ & $\mathrm{G}$ & 1.131 & $1.062-1.204$ \\
\hline
\end{tabular}

B, Comparison between control group and SCD group

\begin{tabular}{|c|c|c|c|c|c|}
\hline SNP & Allele & P-value & Risk allele & Odds ratio & $95 \% \mathrm{CI}$ \\
\hline rs2389202 & $\mathrm{A}>\mathrm{T}$ & 0.018 & $\mathrm{~A}$ & 1.540 & $1.061-2.233$ \\
\hline rs 12429889 & $\mathrm{~T}>\mathrm{C}$ & 0.059 & $\mathrm{C}$ & 1.440 & $0.977-2.121$ \\
\hline rs 16866933 & $\mathrm{G}>\mathrm{A}$ & 0.883 & G & 1.012 & $0.861-1.190$ \\
\hline rs 10183640 & $\mathrm{G}>\mathrm{A}$ & 0.114 & $\mathrm{G}$ & 0.881 & $0.756-1.028$ \\
\hline rs 11187837 & $\mathrm{~A}>\mathrm{G}$ & 0.001 & A & 1.227 & $1.074-1.403$ \\
\hline rs597503 & $\mathrm{G}>\mathrm{A}$ & 0.044 & A & 1.071 & $0.996-1.152$ \\
\hline rs 12155623 & $\mathrm{~A}>\mathrm{T}$ & 0.515 & A & 0.942 & $0.789-1.125$ \\
\hline rs2982694 & $\mathrm{G}>\mathrm{T}$ & $<0.0001$ & $\mathrm{~T}$ & 0.249 & $0.136-0.459$ \\
\hline rs7307780 & $\mathrm{C}>\mathrm{T}$ & 0.045 & $\mathrm{~T}$ & 2.356 & $0.979-5.666$ \\
\hline rs9581094 & $\mathrm{T}>\mathrm{C}$ & 0.233 & $\mathrm{~T}$ & 1.010 & $0.991-1.028$ \\
\hline rs 4621553 & $\mathrm{G}>\mathrm{A}$ & 0.049 & G & 0.594 & $0.351-1.003$ \\
\hline rs 10829156 & $\mathrm{G}>\mathrm{A}$ & 0.392 & G & 1.034 & 0.956-1.119 \\
\hline rs2281680 & $\mathrm{G}>\mathrm{A}$ & 0.774 & $\mathrm{G}$ & 1.014 & $0.922-1.115$ \\
\hline rs2251393 & $\mathrm{G}>\mathrm{A}$ & 0.433 & G & 1.413 & $0.591-3.382$ \\
\hline rs 16942421 & $\mathrm{G}>\mathrm{A}$ & 0.003 & $\mathrm{G}$ & 1.074 & $1.016-1.136$ \\
\hline
\end{tabular}

C, Comparison between CHD group and SCD group

\begin{tabular}{|c|c|c|c|c|c|}
\hline SNP & Allele & $\mathrm{P}$-value & Risk allele & Odds ratio & $95 \% \mathrm{CI}$ \\
\hline rs2389202 & $\mathrm{A}>\mathrm{T}$ & 0.437 & $\mathrm{~A}$ & 1.193 & $0.765-1.860$ \\
\hline rs 12429889 & $\mathrm{~T}>\mathrm{C}$ & 0.001 & $\mathrm{C}$ & 2.547 & $1.406-4.614$ \\
\hline rs 16866933 & $\mathrm{G}>\mathrm{A}$ & 0.024 & $\mathrm{G}$ & 1.253 & $1.032-1.521$ \\
\hline rs 10183640 & $\mathrm{G}>\mathrm{A}$ & 0.001 & $\mathrm{G}$ & 1.372 & $1.144-1.645$ \\
\hline rs 11187837 & $\mathrm{~A}>\mathrm{G}$ & 0.400 & $\mathrm{~A}$ & 0.938 & $0.807-1.091$ \\
\hline rs597503 & $\mathrm{G}>\mathrm{A}$ & 0.550 & $\mathrm{~A}$ & 1.028 & $0.939-1.126$ \\
\hline rs 12155623 & $\mathrm{~A}>\mathrm{T}$ & 0.052 & $\mathrm{~A}$ & 1.219 & $1.001-1.485$ \\
\hline rs2982694 & $\mathrm{G}>\mathrm{T}$ & $<0.0001$ & $\mathrm{~T}$ & 7.484 & $3.262-17.171$ \\
\hline rs7307780 & $\mathrm{C}>\mathrm{T}$ & 0.292 & $\mathrm{~T}$ & 0.610 & $0.240-1.551$ \\
\hline rs9581094 & $\mathrm{T}>\mathrm{C}$ & 0.186 & $\mathrm{~T}$ & 1.027 & $0.990-1.066$ \\
\hline rs4621553 & $\mathrm{G}>\mathrm{A}$ & $<0.0001$ & $\mathrm{G}$ & 4.717 & $2.121-10.490$ \\
\hline
\end{tabular}


Table IV. Continued.

\begin{tabular}{|c|c|c|c|c|c|}
\hline SNP & Allele & P-value & Risk allele & Odds ratio & $95 \% \mathrm{CI}$ \\
\hline rs10829156 & $\mathrm{G}>\mathrm{A}$ & $<0.0001$ & G & 1.494 & $1.286-1.735$ \\
\hline rs2281680 & $\mathrm{G}>\mathrm{A}$ & 0.433 & G & 0.964 & $0.879-1.058$ \\
\hline rs2251393 & $\mathrm{G}>\mathrm{A}$ & 0.869 & G & 0.925 & $0.364-2.349$ \\
\hline rs16942421 & $\mathrm{G}>\mathrm{A}$ & 0.237 & $\mathrm{G}$ & 1.052 & 0.969-1.142 \\
\hline
\end{tabular}

SNP, single nucleotide polymorphism; CHD, coronary heart disease; SCD, sudden coronary death; CI, confidence interval.

Statistical analysis. Microsoft Excel 2010 (Microsoft Corp.) and SPSS 23.0 software (IBM Corp.) were used to record and analyze the data. The prediction data of CHD were obtained by comparing the control and CHD groups, while the prediction data of SCD were obtained by comparing the control and SCD groups and the prediction data of sudden death from CHD were obtained by comparing the CHD and SCD groups. Odds ratio (OR) values were obtained using the $\chi^{2}$ test. $\mathrm{P}<0.05$ was considered to indicate a statistically significant difference. To evaluate the contribution of SNPs to CHD, SCD or sudden death from CHD, two types of prediction models were established: i) The statistically significant SNPs obtained via the $\chi^{2}$ test was added into the prediction model to assess the risk of disease. The predicted probabilities were compared with observed disease status, whereas the area under the receiver operating characteristic curve (AUC) was derived as an overall measurement of prediction accuracy, including sensitivity and specificity measured at different probability thresholds, and the true area was set at 0.5 (an AUC value of 0.5 signified complete lack of prediction and 1.0 perfect prediction). Multifactor dimensionality reduction (MDR) was used to assess the potential effect of whether the model improved prediction accuracy and SNP-SNP interactions. ii) All polymorphic SNPs as variables or covariates evaluated by binary logistic regression and obtained association SNPs were incorporated into the prediction model. The AUC and MDR were used to evaluate the ability of the multi-SNPs to identify and predict diseases.

\section{Results}

Establishment of the mini-sequencing assay. The present study established a mini-sequencing system for screening SCD-related SNPs following extensive adjustment of the multiplex PCR and primers. PCR with short fragment amplification (132-280 bp) was performed, which is easily detected even in degraded samples in forensic casework. All degraded samples were fully typed in the present study. Fig. 1 presents the results of genotyping of 21 SNPs from a random individual sample in the control group.

Genotype data in the Chinese Han population. The present study focused on 21 candidate SNPs from difference loci previously reported by Aouizerat et al (14) via GWAS. A total of six SNPs (rs11624056, rs4665058, rs17718586, rs17291650, rs12189362 and rs1559040) that were reported as

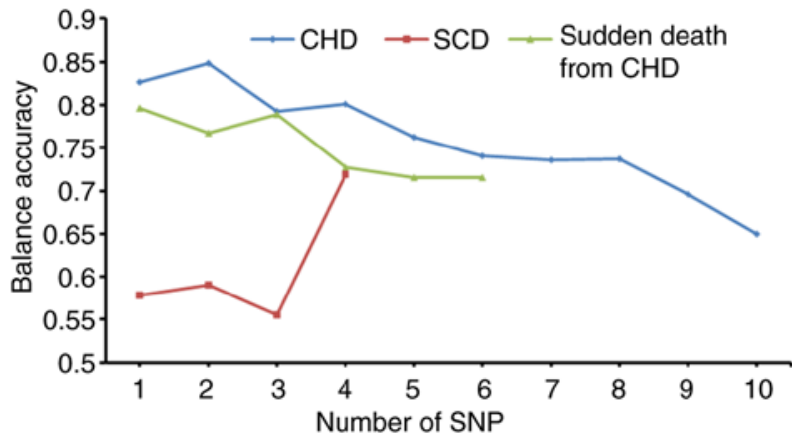

Figure 3. MDR results of the prediction models that added SNPs obtained via the $\chi^{2}$ test. Blue represents the prediction model of CHD, red represents the prediction model of SCD and green represents the prediction model of sudden death from CHD. The statistical results of MDR are presented in Table SIII (balance accuracy testing). The results demonstrated that as the number of predictive model SNPs increased and the testing accuracy of models exhibited a downward trend, particularly the models of CHD and sudden death from CHD. SNP, single nucleotide polymorphism; CHD, coronary heart disease; SCD, sudden coronary death; MDR, multifactor dimensionality reduction.

disease-prone in the GWAS did not exhibit any polymorphism in the population assessed, suggesting a different genetic background between Chinese and European populations. A total of 15 SNPs were polymorphic in the Chinese Han population, including rs2389202, rs12429889, rs16866933, rs10183640, rs11187837, rs597503, rs12155623, rs2982694, rs7307780, rs9581094, rs4621553, rs10829156, rs2281680, rs2251393 and rs16942421. Genotype data for these 15 SNPs are presented in Fig. 2 and Table SII. A total of 10 SNPs (rs2389202, rs12429889, rs16866933, rs10183640, rs11187837, rs597503, rs9581094, rs4621553, rs10829156 and rs16942421) were associated with CHD and four SNPs (rs2389202, rs11187837, rs2982694 and rs16942421) were associated with SCD. Furthermore, six SNPs (rs12429889, rs16866933, rs10183640, rs2982694, rs4621553 and rs10829156) were identified as risk factors for sudden death in patients with CHD. The OR values of the 15 SNPs in the three groups are presented in Table IV. These genotype data contribute to the accumulating evidence on the influence of genetic variation on the risk of CHD and SCD.

Prediction model analysis via the $\chi^{2}$ test and binary logistic regression. The statistically significant SNPs were sequentially added into the prediction model to evaluate the accuracy by the AUC and MDR. The results demonstrated that, as the number 

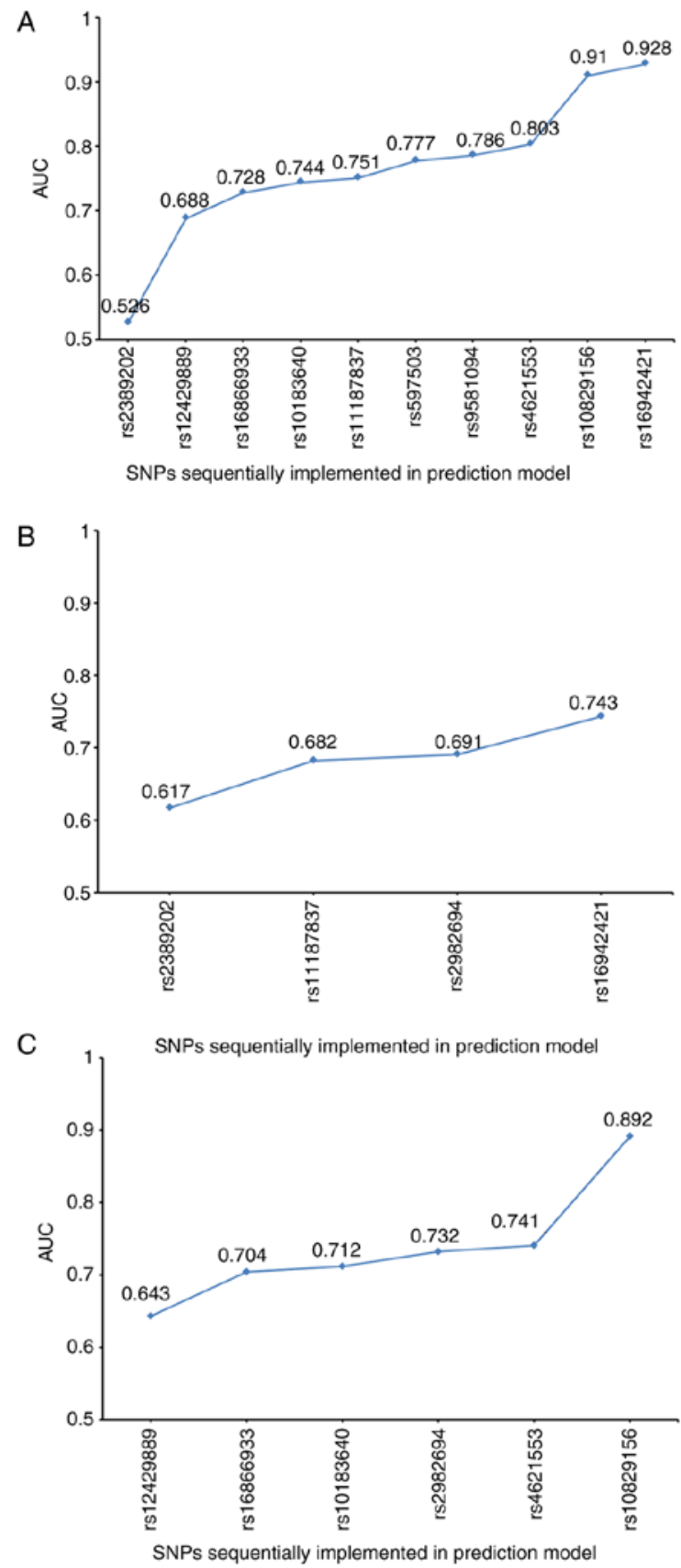

Figure 4. Results of the AUC of the prediction models that added SNPs obtained via the $\chi^{2}$ test with 10,4 and 6 SNPs, respectively. (A) AUC values of the prediction model of CHD. (B) AUC values of the prediction model of SCD. (C) AUC values of the prediction model of sudden death from CHD. The statistical results of AUC are presented in Table SIV (Region). The results demonstrated that, as the number of predictive model SNPs increased, the testing accuracy of models exhibited an upward trend. SNP, single nucleotide polymorphism; CHD, coronary heart disease; SCD, sudden coronary death; AUC, area under the receiver operating characteristic curve.

of predictive model SNPs increased, the testing accuracy of models exhibited a downward trend by MDR (Fig. 3); however, the AUC exhibited an upward trend (Fig. 4). MDR data are presented in Fig. 5 and Table SIII. According to entropy-based analysis, this interaction is redundant (redundant information from both factors). Rs10829156 and rs12429889 treated independently explains 33.62 and $18.60 \%$ of entropy (it removes 33.62 and $18.60 \%$ of 'uncertainty' in CHD determination), respectively. The entropy of interaction between these two
SNPs was $-18.60 \%$, suggesting that this part of the variation in the determination of CHD is common for both SNPs (Fig. 5A). Similarly, rs2982694 and rs11187837 treated independently explains 6.89 and $6.00 \%$ of entropy (it removes 6.89 and $6.00 \%$ of 'uncertainty' in the SCD determination), respectively. The entropy of interaction between these two SNPs was $-7.45 \%$, suggesting that this part of the variation in the determination of SCD is common for both SNPs (Fig. 5B). The AUC values of the prediction models for CHD, SCD and sudden death from CHD are presented in Table SIV. Taken together, these results suggested that feasibly incorporated statistically significant SNPs in the prediction models may be used to predict the occurrence of CHD or SCD.

To identify a better prediction model, the role of the 15 polymorphic SNPs in CHD or SCD was assessed via binary logistic regression. The predicted probabilities were compared with the observed disease status and the AUC was derived as an overall measurement of prediction accuracy. These SNPs were added to the prediction model and interactions were analyzed by MDR. The results demonstrated that as the number of SNPs increased, the testing accuracy of models exhibited a steady or slight upward trend (Fig. 6), which achieved an improved prediction effect. MDR data are presented in Fig. 7 and Table V. The AUC values of these prediction models determined via binary logistic regression were $>90 \%$ (Fig. 8). The SNPs of each prediction model are listed in Table VI. Taken together, these results suggested that the high efficiency of these models may provide prediction results for certain individuals.

\section{Discussion}

Despite extensive research on the etiology, pathogenesis and risk factors of SCD in recent years, strategies for its prevention and treatment remain insufficient. In addition, the interpretation of GWAS remains difficult. A key limitation of GWAS is that it only depicts associations, not causation. Furthermore, their clinical utility remains to be evaluated in prospective studies together with established risk factors in the present study. In the present study, a mini-sequencing detection system was established containing 21 putative SNPs that have been reported to be associated with sudden cardiac arrest via GWAS. The association of these SNPs with the risk of CHD or SCD in the Chinese Han population was assessed. The results confirmed that 15 SNPs were polymorphic in the Chinese Han population. Different prediction models were constructed for these 15 SNPs to evaluate the risk of CHD, SCD and sudden death from CHD. These models may provide a prediction for a significant proportion of individuals and may be useful to provide a novel detection and evaluation method for the prevention and treatment of CHD and SCD in the future.

The genetic architecture of human complex traits substantially differs. Given that the majority of GWAS were performed in European-descent individuals, SNPs from these GWAS may not be transferrable to individuals from other populations, highlighting the importance of diversification of GWAS into non-European populations. No polymorphism was detected in six SNPs in the Chinese Han population, including rs11624056, rs4665058, rs17718586, rs17291650, rs12189362 and rs1559040. In addition, 10 SNPs were associated with CHD, four SNPs were associated with SCD and six SNPs were 

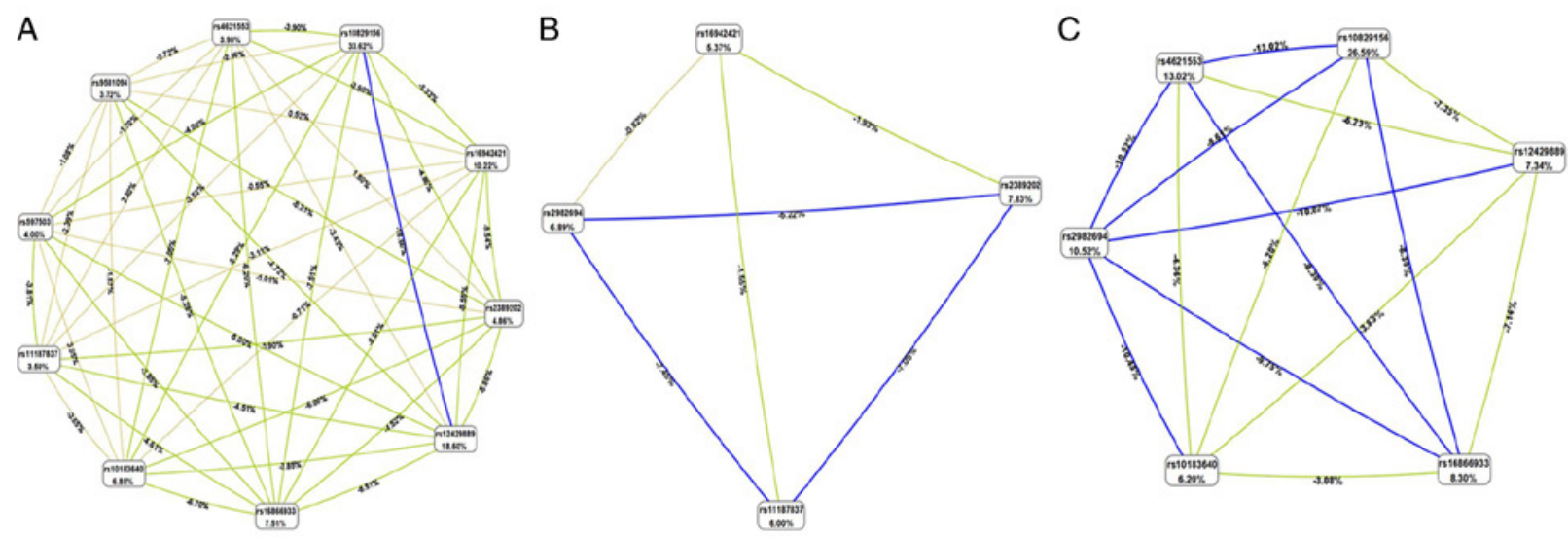

Figure 5. Entropy-based interaction graph from MDR analysis. MDR results of the prediction models that added SNPs obtained via the $\chi^{2}$ test, with 10,4 and 6 SNPs, respectively. (A) Prediction model of CHD. (B) Prediction model of SCD. (C) Prediction model of sudden death from CHD. Entropy values in the cells of individual SNPs indicate the main independent effects. Entropy values marked on the lines connecting two SNPs represent the entropy of interaction. Blue lines indicate a high degree of redundancy, green lines indicate a reduced degree of redundancy and yellow lines represent independence or additivity. SNP, single nucleotide polymorphism; CHD, coronary heart disease; SCD, sudden coronary death; MDR, multifactor dimensionality reduction.

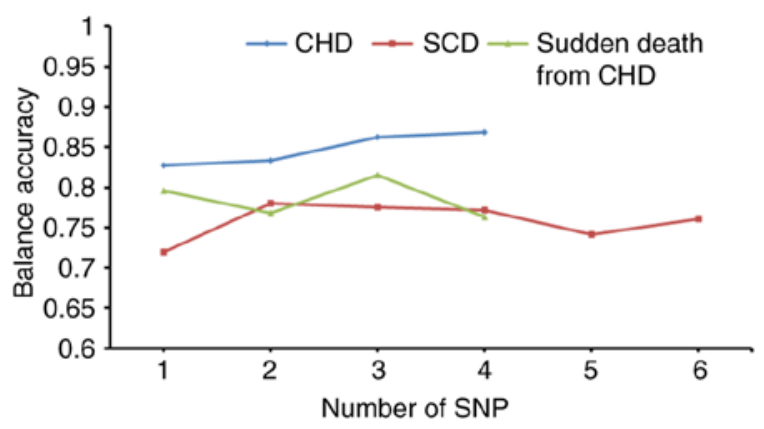

Figure 6. MDR results of the prediction models that added SNPs via binary logistic regression. Blue represents the prediction model of CHD, red represents the prediction model of SCD and green represents the prediction model of sudden death from CHD. The statistical results of MDR are presented in Table $\mathrm{V}$ (balance accuracy testing). The results demonstrated that as the number of SNPs increased, the testing accuracy of models exhibited a steady or slight upward trend, which achieved a better prediction effect. SNP, single nucleotide polymorphism; CHD, coronary heart disease; SCD, sudden coronary death; MDR, multifactor dimensionality reduction.

associated with sudden death from CHD. This confirmed that gene variations exert different effects in different populations. Furthermore, whether these results represent an association of genetic variation with the phenotype $\mathrm{CHD}$ or SCD requires further investigation.

In the present study, the prediction model obtained via the $\chi^{2}$ test was required to be combined with additional SNPs to achieve the same prediction probability as the prediction model obtained via binary logistic regression. Furthermore, the prediction model obtained via the $\chi^{2}$ test was less capable of predicting SCD compared with the prediction model obtained via binary logistic regression. Thus, the prediction model obtained via binary logistic regression is more effective to assess and predict the risk of CHD, SCD or sudden death from CHD.

Previous studies have demonstrated that differences in gene expression result in different physical and pathological traits (31). The rs11187837 locus is situated in the intron region of the phospholipase $\mathrm{C} \varepsilon 1$ (PLCE1) gene
(GRCh38.p12). A previous study reported that differentially expressed genes of PLCE1 may have a critical role in atrial myocyte hypertrophy (32). The rs10183640 variation is located at the junction of activin A receptor type 1 (ACVR1) and the uridine phosphorylase 2 gene (GRCh38.p12). Previous studies have demonstrated that the ACVR1 gene was closely associated with cardiac fibroblasts, aortic valve development and endocardia cushion formation (33-35). Differentially expressed genes of ACVR1 may be predictors for decreased left ventricular ejection fraction and help diagnose congenital heart defects (36-38). The rs4621553 locus is located at the junction of the YTH domain containing 2 and potassium calcium-activated channel subfamily $\mathrm{N}$ member 2 (KCNN2) genes (GRCh38.p12). Previous studies reported that KCNN2 gene variation may have an important role in the development of coronary artery aneurysms and may act as adjunctive markers for risk stratification in patients susceptible to $\operatorname{SCD}(39,40)$. The rs12429889 locus is located at the junction of the Kruppel-like factor 12 (KLF12) and RNY1 pseudogene 5 genes (GRCh38.p12). GWAS reported that KLF12 genes are associated with an increased risk of ventricular arrhythmia, syncope and SCD $(41,42)$. The rs597503 locus is located at the junction of the SCML2 pseudogene 1 and laminin subunit $\alpha 1$ genes (GRCh38.p12). A study on 1,414 Hispanics demonstrated that LAMA1 gene variants are strongly associated with cardio-metabolic traits (43). In addition, Aouizerat et al (14) confirmed that rs2389202, rs16942421, rs16866933, rs9581094 and rs10829156 are risk factors of CAD. Of note, rs2982694 was reported to be associated with SCD rather than CAD in the present study. Several genetic association studies of estrogen receptor 1 (ESR1) gene variants concerning CAD have been published $(44,45)$. It has been suggested that ESR1 is a potential candidate gene during acute coronary events, such as acute thrombotic cardiovascular diseases and atherosclerosis to plaque rupture (46-48). In addition, the ESR1 gene regulates the expression of multiple genes following activation by estrogen in cardiovascular disease (49-51). Previous studies have demonstrated that ESR1 polymorphism was associated with atherosclerosis in coronary arteries, the presence of coronary thrombosis and myocardial infarction, and was 

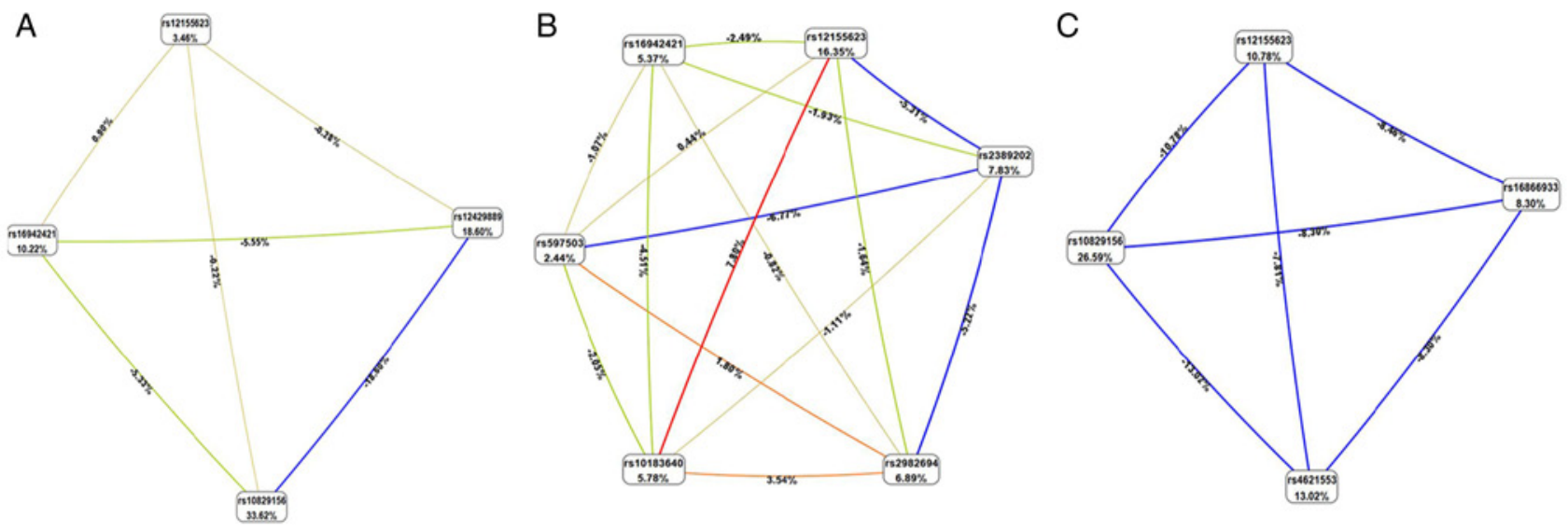

Figure 7. Entropy-based interaction graph from MDR analysis. MDR results of the prediction models that added SNPs via binary logistic regression, with 4, 6 and 4 SNPs, respectively. (A) Prediction model of CHD. (B) Prediction model of SCD. (C) Prediction model of sudden death from CHD. Entropy values in the cells of individual SNPs indicate the main independent effects. Entropy values marked on the lines connecting two SNPs represent the entropy of interaction. Blue lines indicate a high degree of redundancy, green lines indicate a reduced degree of redundancy, yellow lines represent independence or additivity and red lines represent an increased degree of independence. SNP, single nucleotide polymorphism; CHD, coronary heart disease; SCD, sudden coronary death; MDR, multifactor dimensionality reduction.

associated with an elevated risk of CHD in males $(46,52,53)$. Whether rs 2982694 is associated with CAD or other cardiac diseases requires further investigation.

CHD and SCD are associated with genetic complexities. The results of the present study indicated that the four SNPs, rs12429889, rs10829156, rs16942421 and rs12155623, are able to predict CHD, the six SNPs, rs2389202, rs2982694, rs10183640, rs597503, rs16942421 and rs12155623, are able to predict SCD and the four SNPs, rs16866933, rs4621553, rs10829156 and rs12155623, are able to predict sudden death from CHD. In the present study, the AUC values of these prediction models were $>90 \%(\mathrm{P}<0.0001$; Table VI). Taken together, the results of the present study have achieved considerable progress in assessing and predicting CHD, SCD and sudden death from CHD. However, improving the prediction accuracy for CHD or SCD will need to rely on the identification of more associated DNA variants and additional sample sizes, which will be a continuous and accumulative effort, but is certainly achievable in the future.

These SNPs have so far not been used in clinical and forensic prediction and diagnosis of CHD, SCD or sudden death from CHD. The 15 polymorphic SNPs were confirmed in the Chinese Han population ( $n=198$ ), which may help further understand the pathogenesis of SCD. The purpose of establishing this detection system and prediction models was to achieve a forensic assistant identification and genetic diagnosis of SCD, and to provide a basis for gene therapy. The screening of susceptible genes of CHD or SCD in relatives may provide guidance for their lifestyle and medication, as well as a basis for precision medicine.

A key limitation of the present study is that the CHD and SCD samples were collected from different individuals. In addition, the prediction model is only based on 198 samples from the North Chinese Han population and certain patients with CHD and those who passed away from SCD cannot be traced. Furthermore, it is difficult to predict whether patients with CHD may experience sudden death in the future.
The present study focused on SNPs associated with SCD and the SCD samples collected had an uneven sex ratio (4:1). Thus, CHD and normal control samples of patients whose clinical characteristics [with an uneven sex ratio (4:1)] were consistent with those of the SCD group were collected to control for the variables. No statistically significant differences were observed in terms of age or sex distribution and the presence of any underlying diseases among the three groups, suggesting that these variables were evenly distributed among the groups. The purpose of this process is to minimize the interference of other factors with the prediction model to improve the accuracy of prediction.

In the present study, the $\mathrm{SNaPshot}$ assay was performed using multiplex PCR, SBE and CE techniques. The mini-sequencing technology uses a dideoxynucleotide termination method to ligate a fluorescent ddNTP to the 3'-end of an SBE primer to obtain a fluorescent deoxynucleotide sequence. This technique is widely adopted in DNA laboratories due to its high accuracy and sensitivity. There are several technical methods for screening SNPs, such as Sanger sequencing of exons, WGS and WES based on next-generation sequencing (NGS) techniques. Sanger sequencing and mini-sequencing methods are considered more accurate compared with NGS. NGS is expensive and time-consuming and is not applicable to degraded DNA. In clinical and forensic practice, delay-examination and environmental exposure of formaldehyde-fixed samples frequently lead to degradation of tissues, which results in decreased DNA quality for WGS or WES detection (54). In the present experiment, tissues from the SCD group and subjects with death for other causes were degraded due to formaldehyde fixation (fixation period varies from 1 month to 3 years). Not every DNA laboratory is equipped with an NGS instrument to detect this prevailing disease. Using the method of the present study is more feasible to detect degraded DNA samples and more compatible with regular DNA laboratories to meet the increasing requirement of detecting this global disease.

In the present study, 15 polymorphic SNPs associated with CHD or SCD were identified and their predictive value 
Table V. Multifactor dimensionality reduction results of the prediction models which added SNPs obtained by binary logistic regression.

A, Prediction model of CHD

\begin{tabular}{|c|c|c|c|c|c|}
\hline Step & SNPs & $\begin{array}{c}\text { Balance } \\
\text { accuracy } \\
\text { training }\end{array}$ & $\begin{array}{c}\text { Balance } \\
\text { accuracy } \\
\text { testing }\end{array}$ & $\begin{array}{c}\mathrm{CV} \\
\text { consistency }\end{array}$ & $\chi^{2}$ (P-value) \\
\hline 1 & rs10829156 & 0.8267 & 0.8267 & $10 / 10$ & $\begin{array}{c}62.1767 \\
(<0.0001)\end{array}$ \\
\hline 2 & rs10829156, rs 16942421 & 0.8482 & 0.8338 & $8 / 10$ & $\begin{array}{l}70.2788 \\
(<0.0001)\end{array}$ \\
\hline 3 & rs10829156, rs 16942421, rs 12155623 & 0.8629 & 0.8629 & $10 / 10$ & $\begin{array}{l}76.3077 \\
(<0.0001)\end{array}$ \\
\hline 4 & $\begin{array}{l}\text { rs12429889, rs10829156, rs } 16942421 \\
\text { rs12155623 }\end{array}$ & 0.8757 & 0.869 & $10 / 10$ & $\begin{array}{l}81.8735 \\
(<0.0001)\end{array}$ \\
\hline
\end{tabular}

B, Prediction model of SCD

\begin{tabular}{|c|c|c|c|c|c|}
\hline Step & SNPs & $\begin{array}{c}\text { Balance } \\
\text { accuracy } \\
\text { training }\end{array}$ & $\begin{array}{c}\text { Balance } \\
\text { accuracy } \\
\text { testing }\end{array}$ & $\begin{array}{c}\mathrm{CV} \\
\text { consistency }\end{array}$ & $\chi^{2}$ (P-value) \\
\hline 1 & rs12155623 & 0.7201 & 0.7201 & $10 / 10$ & $\begin{array}{c}24.0998 \\
(<0.0001)\end{array}$ \\
\hline 2 & rs10183640, rs 12155623 & 0.8066 & 0.7796 & $10 / 10$ & $\begin{array}{c}50.2438 \\
(<0.0001)\end{array}$ \\
\hline 3 & rs 10183640, rs597503, rs 12155623 & 0.8392 & 0.7757 & $8 / 10$ & $\begin{array}{c}58.5882 \\
(<0.0001)\end{array}$ \\
\hline 4 & $\begin{array}{l}\text { rs2982694, rs10183640, rs597503, } \\
\text { rs12155623 }\end{array}$ & 0.8634 & 0.7718 & $7 / 10$ & $\begin{array}{c}64.916 \\
(<0.0001)\end{array}$ \\
\hline 5 & $\begin{array}{l}\text { rs2389202, rs10183640, rs597503, } \\
\text { rs16942421, rs12155623 }\end{array}$ & 0.8851 & 0.7413 & $6 / 10$ & $\begin{array}{l}73.5285 \\
(<0.0001)\end{array}$ \\
\hline 6 & $\begin{array}{l}\text { rs2389202, rs2982694, rs10183640, } \\
\text { rs597503, rs16942421, rs12155623 }\end{array}$ & 0.899 & 0.7601 & $10 / 10$ & $\begin{array}{c}83.8712 \\
(<0.0001)\end{array}$ \\
\hline
\end{tabular}

C, Prediction model of sudden death from CHD

\begin{tabular}{|c|c|c|c|c|c|}
\hline Step & SNPs & $\begin{array}{c}\text { Balance } \\
\text { accuracy } \\
\text { training }\end{array}$ & $\begin{array}{c}\text { Balance } \\
\text { accuracy } \\
\text { testing }\end{array}$ & $\begin{array}{c}\mathrm{CV} \\
\text { consistency }\end{array}$ & $\chi^{2}(\mathrm{P}$-value $)$ \\
\hline 1 & rs10829156 & 0.7962 & 0.7962 & $10 / 10$ & $\begin{array}{l}42.6898 \\
(<0.0001)\end{array}$ \\
\hline 2 & rs16866933, rs 10829156 & 0.7975 & 0.7677 & $8 / 10$ & $\begin{array}{l}42.6898 \\
(<0.0001)\end{array}$ \\
\hline 3 & rs16866933, rs4621553, rs 10829156 & 0.8245 & 0.8151 & $9 / 10$ & $\begin{array}{c}50.9111 \\
(<0.0001)\end{array}$ \\
\hline 4 & $\begin{array}{l}\text { rs16866933, rs4621553, rs 10829156, } \\
\text { rs12155623 }\end{array}$ & 0.8364 & 0.7628 & $10 / 10$ & $\begin{array}{c}53.857 \\
(<0.0001)\end{array}$ \\
\hline
\end{tabular}

SNP, single nucleotide polymorphism; CHD, coronary heart disease; SCD, sudden coronary death; CV, cross validation.

was determined from 198 samples from the Chinese Han population. Prediction accuracies were expressed as AUC values $>0.9$. Although these prediction models have not been introduced in clinical practice, the preliminary genetic model 
Table VI. SNPs included in each prediction model.

\begin{tabular}{|c|c|c|c|c|c|c|}
\hline \multirow{2}{*}{$\begin{array}{l}\text { Predicted } \\
\text { disease }\end{array}$} & \multicolumn{3}{|c|}{ Prediction model obtained by $\chi^{2}$ test } & \multicolumn{3}{|c|}{$\begin{array}{l}\text { Prediction model obtained by binary logistic } \\
\text { regression }\end{array}$} \\
\hline & SNP & AUC & MDR & SNP & AUC & MDR \\
\hline CHD & $\begin{array}{l}\text { rs2389202, rs12429889, } \\
\text { rs16866933, rs 10183640, } \\
\text { rs11187837, rs597503, } \\
\text { rs9581094, rs4621553, } \\
\text { rs10829156, rs } 16942421\end{array}$ & 0.928 & 0.65 & $\begin{array}{l}\text { rs12429889, rs10829156, } \\
\text { rs16942421, rs12155623 }\end{array}$ & 0.928 & 0.869 \\
\hline SCD & $\begin{array}{l}\text { rs2389202, rs11187837, } \\
\text { rs2982694, rs16942421 }\end{array}$ & 0.743 & 0.7191 & $\begin{array}{l}\text { rs } 2389202, \mathrm{rs} 2982694, \\
\text { rs10183640, rs597503, } \\
\text { rs16942421, rs } 12155623\end{array}$ & 0.922 & 0.7601 \\
\hline $\begin{array}{l}\text { Sudden death } \\
\text { from CHD }\end{array}$ & $\begin{array}{l}\mathrm{rs} 12429889, \mathrm{rs} 16866933 \\
\mathrm{rs} 10183640, \mathrm{rs} 2982694, \\
\mathrm{rs} 4621553, \mathrm{rs} 10829156\end{array}$ & 0.892 & 0.7156 & $\begin{array}{l}\text { rs16866933, rs } 4621553 \\
\text { rs10829156, rs12155623 }\end{array}$ & 0.912 & 0.7628 \\
\hline
\end{tabular}

SNP, single nucleotide polymorphism; CHD, coronary heart disease; SCD, sudden coronary death; AUC, area under curve; MDR, multifactor dimensionality reduction.
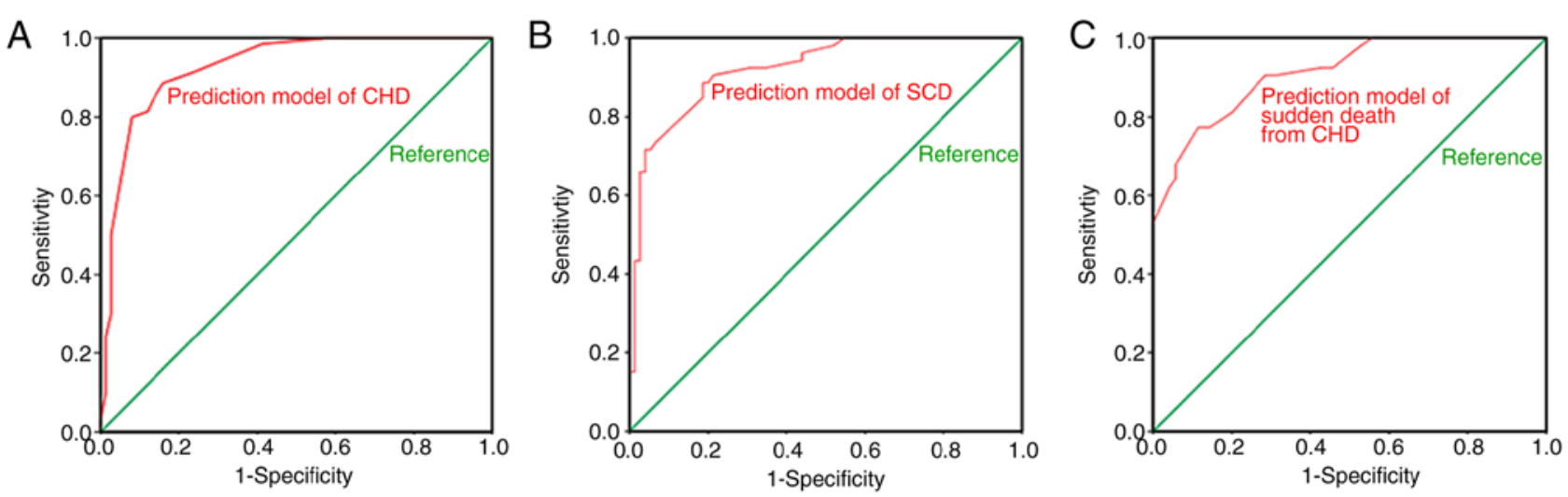

Figure 8. AUC values of the prediction models that added SNPs via binary logistic regression. (A) Prediction model of CHD. (B) Prediction model of SCD. (C) Prediction model of sudden death from CHD. The SNPs of each prediction model and their AUC values were as follows: Four SNPs (rs12429889, rs10829156, rs16942421 and rs12155623) that predict CHD, 0.928; six SNPs (rs2389202, rs2982694, rs10183640, rs597503, rs16942421 and rs12155623) that predict SCD, 0.922; and four SNPs (rs16866933, rs4621553, rs10829156 and rs12155623) that predict sudden death from CHD, 0.912. SNP, single nucleotide polymorphism; CHD, coronary heart disease; SCD, sudden coronary death; MDR, multifactor dimensionality reduction; AUC, area under the receiver operating characteristic curve.

may assist decision-making on CHD, SCD or sudden death from CHD for preventative actions and forensic investigations of the cause of death. Furthermore, the results of the present study suggest that with more genome-wide associated SNPs identified in the future and included in the prediction model together with the SNPs presented here, CHD, SCD or sudden death from CHD will become predictable from DNA, with high accuracy to allow routine practical applications, such as in medicine and forensics.

In conclusion, the present study established a minisequencing detection system containing 21 putative SNPs that have been reported to be associated with sudden cardiac arrest. The results of the $\chi^{2}$ test demonstrated significant associations for 10, 4 and 6 SNPs, in CHD, SCD and sudden death from CHD, respectively. Furthermore, prediction models were established to assess and predict the risk of CHD, SCD or sudden death from CHD. The combination of SNP-associated loci in each group enables the development of a test model with a good predictive performance. Taken together, these results confirm the influence of genetic variation on the risk of $\mathrm{SCD}$ in patients with CHD.

\section{Acknowledgements}

Not applicable.

\section{Funding}

The present study was supported by the Basic Public Welfare Planning Project of Zhejiang Province, China 
(grant no. LGD19C040001), the Sci-Tech Planning Project of Jiaxing, China (grant no. 2020AY30004), the Natural Science Foundation of China (grant no. 30900593), the Shanxi Scholarship Council of China (grant no. 2016-055) and the Key Research and Development Projects of Shanxi Province (grant no. 201803D31069).

\section{Availability of data and materials}

All data generated or analyzed during this study are included in this published article.

\section{Authors' contributions}

GZ and DC conceived and designed the study. GZ and NZ administratively supported the present study. DC and XC performed the majority of the experiments and drafted the manuscript. XL, JW, JDL, JS, JL, BH and DC provided, selected, assembled, analyzed and interpreted the data. GZ and DC confirm the authenticity of all the raw data. All authors contributed toward data analysis, drafting and critically revising the manuscript, and agree to be accountable for all aspects of the work. All authors have read and approved the final manuscript.

\section{Ethics approval and consent to participate}

The present study was approved by the Ethics Committee of Shanxi Medical University (Jinzhong, China; approval no. ZX201601) and written informed consent was provided by all participants or their family members prior to the start of the study.

\section{Patient consent for publication}

Not applicable.

\section{Competing interests}

The authors declare that they have no competing interests.

\section{References}

1. Zegard A, Okafor O, de Bono J, Kalla M,Lencioni M, Marshall H, Hudsmith L, Qiu T, Steeds R, Stegemann B and Leyva F: Myocardial fibrosis as a predictor of sudden death in patients with coronary artery disease. J Am Coll Cardiol 77: 29-41, 2021.

2. Pannone L, Falasconi G, Cianfanelli L, Baldetti L, Moroni F, Spoladore R and Vergara P: Sudden cardiac death in patients with heart disease and preserved systolic function: Current options for risk stratification. J Clin Med 10: 1823, 2021.

3. Michaud K, Magnin V, Faouzi M, Fracasso T, Aguiar D, Dedouit F and Grabherr S: Postmortem coronary artery calcium score in cases of myocardial infarction. Int J Legal Med: Apr 13, 2021. doi: 10.1007/s00414-021-02586-z.

4. Lynge TH, Risgaard B, Banner J, Nielsen JL, Jespersen T, Stampe NK, Albert CM, Winkel BG and Tfelt-Hansen J: Nationwide burden of sudden cardiac death: A study of 54,028 deaths in Denmark. Heart Rhythm: May 7, 2021. doi: 10.1016/j.hrthm.2021.05.005.

5. Silverman MG, Yeri A, Moorthy MV, Camacho Garcia F, Chatterjee NA, Glinge CSA, Tfelt-Hansen J, Salvador AM, Pico AR, Shah R, et al: Circulating miRNAs and risk of sudden death in patients with coronary heart disease. JACC Clin Electrophysiol 6: 70-79, 2020.
6. Goldberger JJ, Basu A, Boineau R, Buxton AE, Cain ME, Canty JM Jr, Chen PS, Chugh SS, Costantini O, Exner DV, et al: Risk stratification for sudden cardiac death: A plan for the future. Circulation 129: 516-526, 2014

7. Khera AV, Mason-Suares H, Brockman D, Wang M, VanDenburgh MJ, Senol-Cosar O, Patterson C, Newton-Cheh C, Zekavat SM, Pester J, et al: Rare genetic variants associated with sudden cardiac death in adults. J Am Coll Cardiol 74: 2623-2634, 2019.

8. Stattin EL, Westin IM, Cederquist K, Jonasson J, Jonsson BA, Mörner S, Norberg A, Krantz P and Wisten A: Genetic screening in sudden cardiac death in the young can save future lives. Int J Legal Med 130: 59-66, 2016.

9. Tsuda T, Fitzgerald KK and Temple J: Sudden cardiac death in children and young adults without structural heart disease: A comprehensive review. Rev Cardiovasc Med 21: 205-216, 2020.

10. Lacaze P, Sebra R, Riaz M, Ingles J, Tiller J, Thompson BA, James PA, Fatkin D, Semsarian C, Reid CM, et al: Genetic variants associated with inherited cardiovascular disorders among 13,131 asymptomatic older adults of European descent. NPJ Genom Med 6: 51, 2021.

11. Johannsen EB, Baughn LB, Sharma N, Zjacic N, Pirooznia M and Elhaik E: The genetics of sudden infant death syndrome-towards a gene reference resource. Genes (Basel) 12: 216, 2021.

12. Valdisser PAMR, Müller BSF, de Almeida Filho JE, Morais Júnior OP, Guimarães CM, Borba TCO, de Souza IP, Zucchi MI, Neves LG, Coelho ASG, et al: Genome-wide association studies detect multiple QTLs for productivity in mesoamerican diversity panel of common bean under drought stress. Front Plant Sci 11: 574674, 2020.

13. Yayla C, Yayla KG and Demirtaş K: Genome-wide association studies in patients with coronary artery disease. Angiology: June 3, 2021. doi: 10.1177/00033197211022076.

14. Aouizerat BE, Vittinghoff E, Musone SL, Pawlikowska L, Kwok PY, Olgin JE and Tseng ZH: GWAS for discovery and replication of genetic loci associated with sudden cardiac arrest in patients with coronary artery disease. BMC Cardiovasc Disord 11: 29, 2011.

15. Ashar FN, Mitchell RN, Albert CM, Newton-Cheh C, Brody JA, Müller-Nurasyid M, Moes A, Meitinger T,Mak A,Huikuri H, et al: A comprehensive evaluation of the genetic architecture of sudden cardiac arrest. Eur Heart J 39: 3961-3969, 2018.

16. Andersen JD, Jacobsen SB, Trudso LC, Kampmann ML, Banner $\mathbf{J}$ and Morling N: Whole genome and transcriptome sequencing of post-mortem cardiac tissues from sudden cardiac death victims identifies a gene regulatory variant in NEXN. Int J Legal Med 133: 1699-1709, 2019.

17. Bastos da Silva I, Batista TP, Martines RB, Kanamura CT, Ferreira IM, Vidal JE and Pereira-Chioccola VL: Genotyping of Toxoplasma gondii: DNA extraction from formalin-fixed paraffin-embedded autopsy tissues from AIDS patients who died by severe disseminated toxoplasmosis. Exp Parasitol 165: 16-21, 2016.

18. Tam V, Patel N, Turcotte M, Bosse Y, Pare G and Meyre D: Benefits and limitations of genome-wide association studies. Nat Rev Genet 20: 467-484, 2019.

19. De R, Bush WS and Moore JH: Bioinformatics challenges in genome-wide association studies (GWAS). Method Mol Biol 1168: 63-81, 2014.

20. Hehir-Kwa JY, Pfundt R and Veltman JA: Exome sequencing and whole genome sequencing for the detection of copy number variation. Expert Rev Mol Diagn 15: 1023-1032, 2015.

21. Meienberg J, Bruggmann R, Oexle K and Matyas G: Clinical sequencing: Is WGS the better WES? Hum Genet 135: 359-362, 2016.

22. Emdin CA, Haas M, Ajmera V, Simon TG, Homburger J, Neben C, Jiang L, Wei WQ, Feng Q, Zhou A, et al: Association of genetic variation with cirrhosis: A multi-trait genome-wide association and gene-environment interaction study. Gastroenterology 160: 1620-1633.e13, 2021.

23. Levin MG, Klarin D, Walker VM, Gill D, Lynch J, Hellwege JN, Keaton JM, Lee KM, Assimes TL, Natarajan P, et al: Association between genetic variation in blood pressure and increased lifetime risk of peripheral artery disease. Arterioscler Thromb Vasc Biol 41: 2027-2034, 2021.

24. Nasu T, Satoh M, Hachiya T, Sutoh Y, Ohmomo H, Hitomi S, Taguchi S, Kikuchi H, Kobayashi T, Takahashi Y, et al: A genome-wide association study for highly sensitive cardiac troponin $\mathrm{T}$ levels identified a novel genetic variation near a RBAK-ZNF890P locus in the Japanese general population. Int J Cardiol 329: 186-191, 2021. 
25. Zinelabidine LH, Torres-Pérez R, Grimplet J, Baroja E, Ibáñez S, Carbonell-Bejerano P, Martínez-Zapater JM, Ibáñez J and Tello J: Genetic variation and association analyses identify genes linked to fruit set-related traits in grapevine. Plant Sci 306: $110875,2021$.

26. Liu J, Li W, Wang J, Chen D, Liu Z, Shi J, Cheng F, Li Z, Ren J, Zhang $\mathrm{G}$ and Yun K: A new set of DIP-SNP markers for detection of unbalanced and degraded DNA mixtures. Electrophoresis 40: $1795-1804,2019$

27. Hu B, Wu T, Zhao Y, Xu G, Shen R and Chen G: Physiological signatures of dual embryonic origins in mouse skull vault. Cell Physiol Biochem 43: 2525-2534, 2017.

28. Dear JD, Sykes JE and Bannasch DL: Quality of DNA extracted from formalin-fixed, paraffin-embedded canine tissues. J Vet Diagn Invest 32: 556-559, 2020.

29. Amemiya K, Hirotsu Y, Oyama T and Omata M: Simple and rapid method to obtain high-quality tumor DNA from clinical-pathological specimens using touch imprint cytology. J Vis Expe 133: 56943, 2018

30. Shi M, Bai R, Yu X, Lv J and Hu B: Haplotype diversity of 22 Y-chromosomal STRs in a southeast China population sample (Chaoshan area). Forensic Sci Int Genet 3: e45-e47, 2009.

31. Hindricks G, Potpara T, Dagres N, Arbelo E, Bax JJ, Blomström-Lundqvist C, Boriani G, Castella M, Dan GA Dilaveris PE, et al: 2020 ESC Guidelines for the diagnosis and management of atrial fibrillation developed in collaboration with the European Association for Cardio-Thoracic Surgery (EACTS): The Task Force for the diagnosis and management of atrial fibrillation of the European Society of Cardiology (ESC) Developed with the special contribution of the European Heart Rhythm Association (EHRA) of the ESC. Eur Heart J 42: 373-498, 2021

32. Chang TH, Chen MC, Chang JP, Huang HD, Ho WC, Lin YS, Pan KL, Huang YK, Liu WH and Wu CC: Exploring regulatory mechanisms of atrial myocyte hypertrophy of mitral regurgitation through gene expression profiling analysis: Role of NFAT in cardiac hypertrophy. PLoS One 11: e0166791, 2016.

33. Hu J, Wang X, Wei SM, Tang YH, Zhou Q and Huang CX: Activin A stimulates the proliferation and differentiation of cardiac fibroblasts via the ERK1/2 and p38-MAPK pathways. Eur J Pharmacol 789: 319-327, 2016.

34. Thomas PS, Sridurongrit S, Ruiz-Lozano P and Kaartinen V: Deficient signaling via Alk2 (Acvr1) leads to bicuspid aortic valve development. PLoS One 7: e35539, 2012.

35. Thomas PS, Rajderkar S, Lane J, Mishina Y and Kaartinen V: AcvR1-mediated BMP signaling in second heart field is required for arterial pole development: Implications for myocardial differentiation and regional identity. Dev Biol 390: 191-207, 2014.

36. Gorący I, Safranow K, Dawid G, Skonieczna-Żydecka K, Kaczmarczyk M, Goracy J, Loniewska B and Ciechanowicz A: Common genetic variants of the BMP4, BMPR1A, BMPR1B, and ACVR1 genes, left ventricular mass, and other parameters of the heart in newborns. Genet Test Mol Biomarkers 16: 1309-1316, 2012.

37. Smith KA, Joziasse IC, Chocron S, van Dinther M, Guryev V, Verhoeven MC, Rehmann H, van der Smagt JJ, Doevendans PA, Cuppen E, et al: Dominant-negative ALK2 allele associates with congenital heart defects. Circulation 119: 3062-3069, 2009.

38. Joziasse IC, Smith KA, Chocron S, van Dinther M, Guryev V, van de Smagt JJ, Cuppen E, Ten Dijke P, Mulder BJ, Maslen CL, et al: ALK2 mutation in a patient with Down's syndrome and a congenital heart defect. Eur J Hum Genet 19: 389-393, 2011

39. Kim JJ, Park YM, Yoon D, Lee KY, Seob Song M, Doo Lee H, Kim KJ, Park IS, Nam HK, Weon Yun S, et al: Identification of $\mathrm{KCNN} 2$ as a susceptibility locus for coronary artery aneurysms in Kawasaki disease using genome-wide association analysis. J Hum Genet 58: 521-525, 2013.

40. Yu CC, Chia-Ti T, Chen PL, Wu CK, Chiu FC, Chiang FT, Chen PS, Chen CL, Lin LY, Juang JM, et al: KCNN2 polymorphisms and cardiac tachyarrhythmias. Medicine (Baltimore) 95: e4312, 2016.
41. Lahrouchi N, Tadros R, Crotti L, Mizusawa Y, Postema PG, Beekman L, Walsh R, Hasegawa K, Barc J, Ernsting M, et al: Transethnic genome-wide association study provides insights in the genetic architecture and heritability of long QT syndrome. Circulation 142: 324-338, 2020

42. Naik A: Long QT syndrome revisited. J Assoc Physicians India 55 (Suppl): S58-S61, 2007.

43. Hellwege JN, Palmer ND, Dimitrov L, Keaton JM, Tabb KL, Sajuthi S, Taylor KD, Ng MC, Speliotes EK, Hawkins GA, et al: Genome-wide linkage and association analysis of cardiometabolic phenotypes in Hispanic Americans. J Hum Genet 62: 175-184, 2017.

44. Maruyama H, Toji H, Harrington CR, Sasaki K, Izumi Y, Ohnuma T, Arai H, Yasuda M, Tanaka C, Emson PC, et al: Lack of an association of estrogen receptor alpha gene polymorphisms and transcriptional activity with Alzheimer disease. Arch Neurol 57: 236-240, 2000

45. Matsubara Y, Murata M, Kawano K, Zama T, Aoki N, Yoshino H, Watanabe G, Ishikawa K and Ikeda Y: Genotype distribution of estrogen receptor polymorphisms in men and postmenopausal women from healthy and coronary populations and its relation to serum lipid levels. Arterioscler Thromb Vasc Biol 17: 3006-3012, 1997.

46. Lehtimäki T, Kunnas TA, Mattila KM, Perola M, Penttilä A, Koivula T and Karhunen PJ: Coronary artery wall atherosclerosis in relation to the estrogen receptor 1 gene polymorphism: An autopsy study. J Mol Med (Berl) 80: 176-180, 2002.

47. Shearman AM, Cupples LA, Demissie S, Peter I, Schmid CH, Karas RH, Mendelsohn ME, Housman DE and Levy D: Association between estrogen receptor alpha gene variation and cardiovascular disease. JAMA 290: 2263-2270, 2003.

48. Herrington DM, Howard TD, Brosnihan KB, McDonnell DP, Li X, Hawkins GA, Reboussin DM, Xu J, Zheng SL, Meyers DA and Bleecker ER: Common estrogen receptor polymorphism augments effects of hormone replacement therapy on E-selectin but not C-reactive protein. Circulation 105: 1879-1882, 2002

49. Henttonen AT, Kortelainen ML, Kunnas TA and Nikkari ST: Estrogen receptor-1 genotype is related to coronary intima thickness in young to middle-aged women. Scand J Clin Lab Invest 67: 380-386, 2007.

50. Yilmaz A, Menevse S, Erkan AF, Ergun MA, Ilhan MN, Cengel A and Yalcin R: The relationship of the ESR 1 gene polymorphisms with the presence of coronary artery disease determined by coronary angiography. Genet Test 11: 367-371, 2007.

51. Boroumand M, Ghaedi M, Mohammadtaghvaei N, Pourgholi L, Anvari MS, Davoodi G, Amirzadegan A, Saadat S, Sheikhfathollahi $M$ and Goodarzynejad H: Association of estrogen receptor alpha gene polymorphism with the presence of coronary artery disease documented by coronary angiography. Clin Biochem 42: 835-839, 2009.

52. Kunnas T, Silander K, Karvanen J, Valkeapaa M, Salomaa V and Nikkari S: ESR1 genetic variants, haplotypes and the risk of coronary heart disease and ischemic stroke in the Finnish population: A prospective follow-up study. Atherosclerosis 211: 200-202, 2010

53. Roszkowska-Gancarz M, Kurylowicz A, Polosak J, Ambroziak M and Puzianowska-Kuznicka M: The -351A/G polymorphism of ESR1 is associated with risk of myocardial infarction but not with extreme longevity. Clin Chim Acta 411: 1883-1887, 2010.

54. Nouws S, Bogaerts B, Verhaegen B, Denayer S, Van Braekel J, Winand R, Fu Q, Crombé F, Piérard D, Marchal K, et al: Impact of DNA extraction on whole genome sequencing analysis for characterization and relatedness of Shiga toxin-producing Escherichia coli isolates. Sci Rep 10: 14649, 2020.

This work is licensed under a Creative Commons Attribution-NonCommercial-NoDerivatives 4.0 International (CC BY-NC-ND 4.0) License. 